\title{
She's Really Kind and Hella Weird! - The Use of Intensifiers among Teens: A Sociolinguistic Analysis
}

\author{
Calista Putri $^{1}$, Hairus Salikin ${ }^{2}$, Dewianti Khazanah ${ }^{3}$ \\ University of Jember, INDONESIA \\ e-mail: calistaputrisavira@gmail.com ${ }^{1}$, hairus@unej.ac.id², dewiantikhazanah.sastra@unej.ac.id ${ }^{3}$
}

\begin{abstract}
The relation of the different uses of intensifiers and gender have been extensively discussed; however, the studies discussing how intensifiers were used differently by Indonesian male and female have been scanty. This study aimed at examining the different ways Indonesian male and female teens used English intensifiers and the factors that account for those differences. The data, garnered from 10 participants (male $\mathrm{N}=5$, female $\mathrm{N}=5$ ) through free writing sections and interviews, were analysed quantitatively and qualitatively. The results of the research show significant differences of the use of intensifiers by Indonesian male and female teens such as the different amounts of intensifiers, the adjective types, the degree, positive-negative evaluation, emotional value, intensifiers choices, and the use of double and taboo intensifiers. The results of the interview confirmed that these differences were due to several gender-related reasons associated with power, politeness, expressions, emotion, and societal pressure.
\end{abstract}

Keywords: Gender roles; intensifiers; language variation; teens.

\section{INTRODUCTION}

The relation between gender and language use has been extensively investigated ever since Lakoff (1975) reported the reflection of women's secondary position through the ways they speak. A plethora of studies exploring this relationship have been done since then and resulted in different and evolving ways of viewing gender roles in language use; from the dominance and cultural approaches (Weatherall, 2002) to communities of practice approach (Eckert \& McConell-Ginet, 2003). Despite the different ways to view the relationship between language and gender roles, one thing remains accepted; that is, several linguistic features are typically associated with the speech of men and women (Weatherall, 2016). Scrutinizing gendered talks is important as they reveal how certain community perceives, maintains, and negotiates masculine and feminine roles in that group. These perceptions continuously become topic of investigations because gender roles nowadays are fast changing (Amir, Abidin, Darus, \& Ismail, 2012).

One linguistic feature reflecting the gender and language association is intensifiers. In general, society has constructed a stereotype that males and females ought to behave differently related to the images of gender roles-masculinity and femininity. In keeping with these assumptions, the use of intensifiers is also determined by gender (Mills \& Francis, 2006). Quirk et al. (1985, p. 445) defines intensifiers as adverbs that modify the degree or strength of another word, such as very, so, really, pretty, absolutely, etc. In similar vein, Murphy (2010) defines intensifiers as adverbs which are used to maximize or boost meanings. How males and females assign and for what purposes each social group employs intensifiers have been central to much research. Karlsson (2007, p. 33) disclosed that female speaks intensifiers like "so" and "such" more frequently than male such as in I really felt so bad about the boy and such a nice boy. This specific use of intensifiers is used to accentuate politeness norms in female's side. In contrast, male can speak slangy and more extreme word such as fucking weird to show their toughness and signal a modern adolescent.

The study by Sardabi and Afghari (2015) reported that in Iran intensifiers were widely used by female students in high school rather than the male students. It reflects how Iranian females are threatened with many social restrictions such as being in a more inferior social status and trapped in regulation of restricted opinion. Therefore, the only way Iranian females signal their position or power is to appeal one of the linguistic devices such as intensifiers. According to a study conducted by Saarenpää (2016) females used 
more intensifiers than males in ICE-CAN (The International Corpus of English: Canada). It is because males are usually perceived as not acquiring newer forms as easily as females. Intensifiers can be functioned as vivid symbols for females to gain power in order to match the material power males possess more in society.

With many researchers studying the use of intensifiers and the relation with gender, little has been known about its realization and its driving factors in the context of Indonesia. To fill this gap, this research was intended to explore the different ways of Indonesian male and female teens in using intensifiers and expounded the factors driving the emergence of the differences. To achieve the goals, the observation of intensifiers in teenagers' language could help in portraying language variation among teens due to the richness of their expression and innovation in creating their own languages (Palacios-Martínez, 2011, p. 115). Many scholars have concluded that teenagers are the highest users of some slang, colloquial style, and even swear words (Andersen \& Hasund, 2002; Moore, 2012; Palacios-Martínez, 2011).

\section{Intensifiers}

According to Quirk et al. (1985, p. 590), intensifiers are divided into two types: amplifiers which consists of maximizers (absolutely, completely, entirely, extremely), boosters (very, badly, bitterly, so) and downtoners which consists of approximators (almost, nearly), compromisers (a bit, little, rather, less), diminishers (partly, only), minimizers, or negative maximizers (hardly, in the least).

Intensifiers towards adjectives are also noticed in eight types of adjective as provided by Dixon (1977, p. 4659). Here are the examples of the intensifiers found in certain types of adjectives:

a) Dimension: He's a real big guy.

b) Physical Property: It was a really hot day

c) Colour: It was really really really red yesterday.

d) Human Propensity: My dad was so happy ... my mom was happy too.

e) Age: He was great but he was also very old.

f) Value: It seemed a very pleasant place.

g) Speed: Like, Canadians are very slow at recognizing their own people.

h) Position: I actually got to Newfoundland which is so far away.

In further observation, Tagliamonte (2008, p. 375) clarified that there is a possibility of such intensifiers that can be functioned as both positive and negative evaluation regarding to its context. Furthermore, intensifiers are also related with the emotional value of the modified adjective (Peters, 1994). Tagliamonte
(2008, p. 380) affirmed that intensifiers expression can encode an emotion as in:

Emotion: "'Cause she's so funny ...she's so mean ... and so evil!"

Non emotion: 'Ijust thought it was like so small."

The term of double intensifiers also existed and was previously explained by Tagliamonte (2008, p. 390). An example in her work is "He's super super selfish." Moreover, Schwizer (2014, p. 8) discovered another form of double intensifier. She claimed that the word so which then followed by some taboo words such as fucking and damn is classified as double intensifiers. Sardabi and Afghari (2015, p. 206) also mentioned that double intensifiers are found in the speech, such as 'That is very, very interesting.' Taboo intensifier was also acknowledged by Bulgin, Elford, Harding, Henley, and Power (2008, p. 112) beforehand. Years ahead, Murphy (2010) added that taboo words and adjective can be developed into adverbs which classified as an intensifier. It was recognized as the characteristics of youths as well (Núñez-Pertejo \& Palacios-Martínez, 2018, p. 146).

\section{Factors influencing the use of intensifiers regarding genders}

Aside from the different linguistic device itself, gender is recognized as an important extra-linguistic factors influencing language use. There are several aspects associated with the impact of gender toward the use of intensifiers between males and females such as:

a. Power

Lakoff (1975) argued that the use of intensifiers show women's lack of power in interaction. She added that the use of intensifiers can also persuade the interlocutors to take them seriously (Lakoff, 1975). In addition, Holmes (1992, p. 316) also stated that intensifiers as boosting devices reflect the speaker anticipation that the addressee may remain unconvinced so that he or she uses intensifiers to supply extra reassurance.

b. Politeness

Brown and Levinson (1987) said that exaggerations are used by the speaker as a politeness strategy to assert interest, approval or sympathy. This strategy is often conducted with intensifying modifiers. For example, "How (absolutely) marvelous/ extraordinary/..." and also "I am (really) sorry to hear about your father." Moreover, in an apology situation, as stated by Sari (2015, p. 10), the double expressions of direct apology "Pardon me, I'm so sorry" gives more emphasize on apology.

c. Expression

Greenbaum (1974) examined that each intensifier tended to produce various expressions. For example, very much is an expression of favorable attitude, and badly is an expression of needing, the 
expressive expletives, such as bloody is an expression of agitation, distastefulness, or even approval.

\section{d. Emotion}

Intensifiers are associated with colloquial usage and nonstandard varieties as well as emotional language (Peters 1994). Previously, Lakoff (1975) stated that women often use expressions of intensifiers as the attempt to express their strong feelings and attitudes since women are more emotionally-oriented in their speech.

e. Societal pressure

Society suggests different roles and positions for men and women. In this vein, Andersen and Hasund (2002) found that females prefer weaker expletives (use really) since females have to mind their speaking. While males are often found to use swear terms (use bloody and fucking) more frequently.

\section{Methods}

This study was informed by the use of qualitative and quantitative methods. However, this study dominantly used qualitative analysis to give detail explanation about how male and female teens are different in using intensifiers and elaborating the way how gender roles can affect the use of intensifiers. The quantitative analysis was also needed to add statistical information about the frequency values and distribution of intensifiers of every speaker.

The data of this study were collected from ten learners (female $\mathrm{N}=5$, male $\mathrm{N}=5$ ) at an English First (EF) course in Jember. The age range of the participants voluntarily recruited was around 14-18 years old. They all joined the same stage called Frontrunner which is equal to intermediate. The first observation of the use of intensifiers between male and female teens was through free writing sections. It was inspired by the work of a similar field from Pérez-Paredes and DíezBedmar (2012, p. 110) in which the participants were asked to write free essays on related topics. In addition, it was also inspired by a study from Corey (2014, p. 161) that the participants described their favourite family vacation, favourite vacation, their best day ever, and worst day ever. In this study, all participants were asked to share stories with five different topics: best day, worst day, favourite things, a person who is being admired, and a person who is being hated. To ease the analysis process, the participants and the themes were coded. The female participants were coded as A(hence A1, A2, A3, A4, an A5) and male participants were coded B (hence B1, B2, B3, B4, and B5). Each theme was coded A, B, C, D, E respectively. After completing the free writing sections, the interview as the second method was used to obtain further data in case of relating their choices of intensifiers with gender perception in society. The type of interview used in this study was one-on-one interview with a semi-structured method. This method was chosen since it had to be personal enough to clarify the reasons of the use of intensifiers in each participant writings. Set of questions were previously arranged based on the several cases that appeared in their writing. However, spontaneous questions might be added in the middle of interview in order to response their feedbacks further. This whole process of interview was conducted in English. All the participants' data displayed in the findings section were also originally in English.

The patterns of intensifiers used by male and female teenagers are interpreted with some theories in details. Every intensifier written was classified into the type of adjectives as Dixon (1977) stated. It was further observed through some viewpoints such as amplifiers and downtoners (Quirk et al, 1985), positive and negative evaluation (Tagliamonte, 2008), emotional value (Tagliamonte, 2008). The later procedure was to analyse their reasons in using such intensifiers. Some supporting theories were used to clarify the motives and gender role factors such as communication and power (Lakoff, 1975; O'Barr,1982) politeness style (Huddleston \& Pullum, 2002), expression (Greenbaum, 1974; Boncea, 2013), emotion (Wardhaugh, 2006), and societal pressure (Andersen \& Hasund, 2002).

\section{FINDINGS AND DISCUSSION}

\section{The use of Intensifiers by male and female participants}

The analysis of the intensifiers of the free writing sections showed that the differences of the use of intensifiers among male and female participants were in two categories: the amount of intensifiers used and different types of intensifiers. Regarding the amount of intensifiers used by male and female participants, it was found that the higher amount of the use of intensifiers was found in female participants. The ratio of female participants' intensifiers in free writing section was $1,92 \%$ (see figure 1) while male participants used $1,61 \%$ intensifiers in their writing section (see figure 2). This finding was in alignment with previous studies which found that intensifiers were dominantly used by females rather than males (Lakoff, 1975; Sardabi \& Afghari, 2015).

The analysis on free writing sections also show different types of intensifiers employed by male and female participants. The types characterizing male and female use of intensifiers were explored as follow: 


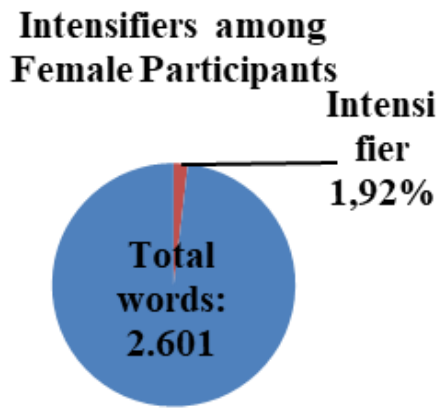

Figure 1. Intensifiers among Female Participants

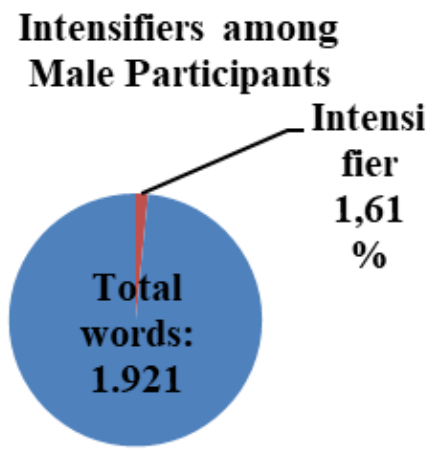

Figure 2. Intensifiers among Male Participants

\section{Ways to intensify adjectives}

The observation towards intensifiers showed that female participants intensified dimension, value, and mostly human propensity adjectives such as in "Turned out she was well known to be super annoying" (A1-E). On the other hand, males did not intensify any dimension adjectives; rather they intensified position adjective, while the rest types of adjectives found were similar to female participants'. The observation also found the different intensifiers to attribute value adjectives. The use of intensifier "so" was a trend among males, and the intensifier "fucking" was a trend among females to attribute value adjectives. Females wrote the word "fucking" six times as in so much fucking fun, fucking amazing, so fucking fun, fucking easy, fucking great, and so fucking mess $u p$, while males wrote three times only. This trend reversed under the human propensity values. Under the human propensity adjectives, males used the word so fucking and females used so in order to intensify human related adjectives. The trend among females was the use of various choices of intensifiers such as extremely, hella, and fully while this thing did not exactly appear among males.

\section{Degree of intensifiers}

From the total of 2601 words of females' writing, there were 50 expressions of intensifiers comprising amplifiers as many as $94 \%$. On the other hand, from 1921 words of males' writing, there were 31 expressions of intensifiers-comprising amplifiers as many as $87 \%$. It could be assumed that females tend to exaggerate expressions or add some extra tense using intensifiers compared to males. Furthermore, females frequently wrote maximizers degree as shown in the sentence: "Super dope! You should listen!" (A2-D). Males did not typically write those expressions because they tend to choose boosters amplifiers such as really, very, and so.

Another finding was the use of combination of boosters and maximizers as in this sentence "I really admired him because he is so fucking legend." (B3-D). This issue appeared eight times among males while only four expressions were found among females. In addition, in male cases, combinations of maximizers plus boosters were also found. This did not appear in females' writing. Here is the expression found in male's writing "When you play it, you might want to play it all the time because they are absolutely very nice to be played." (B4-C)

\section{Positive and negative evaluation}

Males tended to use intensifiers expression to create positive evaluation (79\%) rather than females $(52 \%)$ as in these following sentences:

"I was really happy that day because all of my major family came to my birthday. (B4-A)

"It was so cool and I want to feel it again." (B5-A)

On the other hand, females used intensifiers more frequently to create negative evaluation compared to males such as in these sentences

"Vale ... She's extremely savage:'v, ..."(A1D)

"The other time, was that she was so "lebay" (read: overacting) and so arrogant." (A1-E)

\section{Emotional value}

In male cases, they tended to use double degree of intensifiers $(58 \%)$ to express emotion. The word choices that were mostly found were intensifiers so and really followed by taboo intensifiers fucking or damn as in these following sentences:

"I'm so fucking happy. I'm really thankful." (B3-A)

"I help him a lot. And there's one time that showed me that he is really fucking jerk man." (B4-E)

Females preferred to use single intensifiers to show their emotion towards the sentences such as so (20\%), fucking (16\%), extremely (12\%), really (12\%), super (12\%), etc. as in these following sentences: 
"Billie Eilish is one of the person who I admire so bad." (A3-D)

"I don't know who I admire bcs every ppl in my life is fucking amazing:'v (A1-D)

"I'm extremely happy when my mother allowed me to buy koi watercolor and white gel pen." (A1-C)

These two conditions revealed that emotional and non-emotional value among males and females were actually interchangeable. Males used double degree of intensifiers while females used various choices of single intensifiers.

\section{Choices of intensifiers}

Compared to males, females used more variants in expressing intensifiers such as quite, completely, hella, extremely, terribly, super, kinda, perfectly, etc., as in these below sentences:

"The voice chat was quite long." (A1- A)

"And well that was terribly bad." (A2-B)

In order to observe more specified comparison, the use of every intensifier expression between males and females were depicted through graphic representations. See Figures 3 and 4.

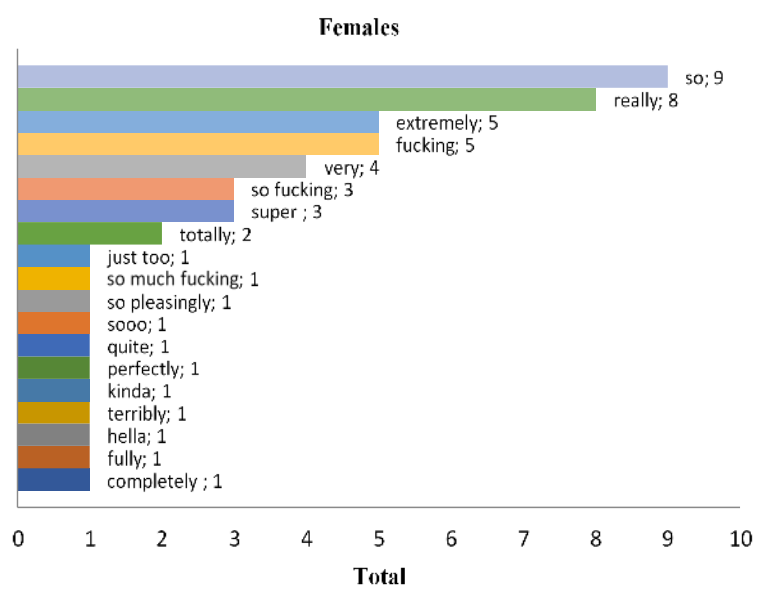

Figure 3. Intensifiers expression among females

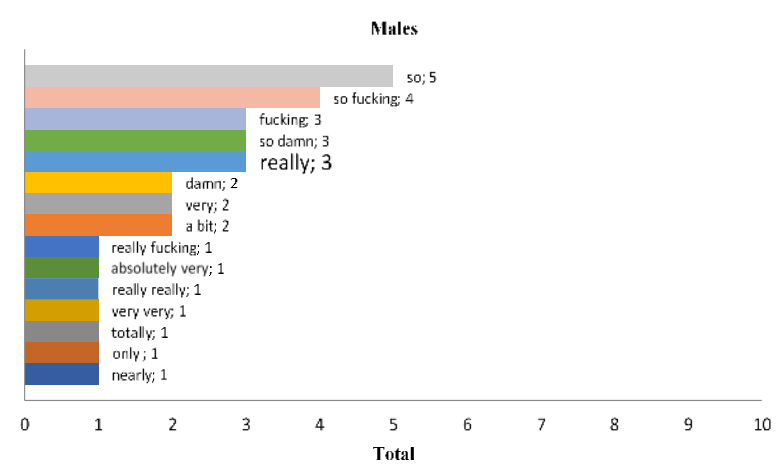

Figure 4. Intensifiers expression among males
In male cases, the three most used intensifiers were the word so, so fucking, and so damn. It shows that males were familiar with intensifiers so. Males also added trendy intensifiers such as fucking and damn. In female cases, this thing was considered as less-used intensifiers. The rest of female choices were single intensifiers such as extremely, super, and totally.

\section{Double intensifiers}

Males used double intensifiers more frequently than females. The first type of double intensifier was the repetition of preceding words or the use of two parallel intensifiers as in these following sentences:

"Why are you not join the class?" I was very very shy that day and I had to say sorry to my friend." (B4-B)

"I have three guitars in my house and they are really really cool." (B4-C)

These sentences supported what Tagliamonte (2008, p. 390) revealed that a person could express double intensifier as in "He's super super selfish." Schwizer (2014) also claimed that there was actually another type of double intensifiers such as the taboo word which also apply or tied to so such as so fucking and so damn as in these sentences:

"I love watching Studygram on Youtube, they are all so pleasingly aesthetic." (A2-C)

"His name is Nafis and he is so damn kind." (B4-D)

\section{Taboo intensifiers}

Males revealed to be the highest user of taboo intensifiers (55\%) with damn and fucking as the mostused expressions. However, the only taboo intensifiers used among females were fucking and hella as in this sentence "I'm sorry I'm exaggerating. But she is really kind and hella weird." (A1-D) Hella was considered as one of American slangs. It was possibly a contraction of "hell of $a$. The word fucking was created either to construct positive or negative situation. Males used the word fucking to create positive situation (75\%) as in these following sentences:

"That was fucking cool. I don't know what is cool, but yeah, it's cool!" (B1-A)

"WOW. I'm so fucking happy. I'm really thankful, ..." (B3-A)

On the other hand, females used this word to express and deliver something negative oriented (67\%). Here are some expressions of the word fucking in negative context by females:

"Nice! What a nice fucking great days!" (A2-B)

"A fucking jerk-ass bitch like her shouldn't be existed.”(A2-E) 
"... as you can see my handwriting is so fucking messed up, so I don't do bujo (bullet journal), ..." (A2-C)

\section{Factors influencing the different intensifiers among male and female participants}

Interview sessions were administered to explain the emergence of different uses of intensifiers by male and female participants. These several gender roles were revealed through these numerous details below:

\section{Power}

Power refers to the force of domination in an interaction; it is a force to control the talk or behaviour of the other. Males were the ones attempting and put intention into their intensifier expressions with regards of power. From the interview, the reason beyond their use of intensifiers which related to power can be seen in this following interview answer:

"I used intensifiers to show power or authority value because males wanted to be heard." (B5)

In male cases, one participant dealt with this power perception. He said that he used intensifiers with an intention to make listeners could take him seriously. $\mathrm{He}$ even made his own generalization that every male wanted to be heard, therefore, intensifiers were there to validate their power in interaction. Meanwhile, this result was actually opposing to what Lakoff (1975) said that intensifiers were closely related to females since they used it in order to show their power in interaction. However, in this study, the use of intensifiers as power sign in interaction was dominantly shown by males.

\section{Politeness}

An opinion which became this study's point of view was from Huddleston and Pullum (2002). They considered that females were not given free chance as expected from society's point of view in using taboo intensifiers in order to fit the politeness norm. Contrary to this perspective, this study did not reveal a similar result. All females told that there were no such politeness boundaries they had to fulfil in uttering intensifiers. All the discussions are presented in the interview answers below:

"I believe that intensifiers are related with power, expression, and emotion. However, I think females do not really care about politeness because we can always say honestly of what we want to talk about" (A1)

"The only way I can think is that females should not always match politeness style."(A2)
All female participants assumed that they did not think about politeness norms. Their uses of intensifiers, even the taboo ones, were only such as telling jokes and perception. It did not mean that they actually cursed but they only told what they felt. In male case, a participant was discovered to partly approve what Brown and Levinson (1987) said:

"I wrote 'nearly dead' since it told about death. I used the word 'nearly' because I didn't have another clue to express about the word 'dead' in a more proper way." (B2)

This result supported Brown and Levinson (1987) statement which told that intensifiers are related with sympathy. Intensifier 'nearly' functioned as a form to create politeness strategy since the writer wanted to show his sympathy that dead was a serious thing to be explained. Therefore, the word nearly was there to lower the effect of the following word which was dead.

\section{Expression}

Males and females in this study both agreed that intensifiers they wrote were forms of their expressions. This result supported a study by Greenbaum (1974) which revealed that each intensifier produced various expressions. There were several motives of expressions are which were shown in these answers from the interview section:

"I used single and also double intensifiers because I wanted to express a lot of exaggeration. $\mathrm{Ya}$, females exaggerate a lot. (AI)

"I used sooo in 'sooo jealous' because I have overwhelming emotional expression." (A1)

"Ya, I used extremely before adjective 'furious'because I am over reacting anything." (A1)

Another motive found was about the expressions of admiration towards something they like. Males and female were also found in this similar motive

"I wrote 'super dope' because it's common expression to express admiration to K-Pop idols among teens like us nowadays." (A2)

"I wrote 'damn rich and polite' to express that I like him because he was so badass (B1)

In contrast with previously mentioned motives, intensifiers were also applied in expressing complaint or grumble

"What a nice fucking great days! I wrote 'fucking great' to express sarcasm. I also gave complaint since 'great days' here was not like the actual meaning. What I mean was 'really bad day', but I chose to write 'fucking great' to express more." (A2) 
The next related expression was about the responses of shock as said by one of participant "'so fucking happy' had meaning of wow expressions because of the big gift I got (B3)

Aside from approval evidence, expletive intensifiers could also provide distastefulness (Greenbaum, 1974). The last expression found was related with this issue. Here is the evidence from the interview answer:

"I used 'hella weird' because I thought about a person madly. Therefore, I used 'hella' to demonstrate what I wanted to express since I really did not like her." (Al)

\section{Emotion}

All participants' answers through the interview method revealed that intensifiers were used to express certain emotions they felt.

"I used taboo intensifiers in order to show my anger or my negative; I think that males don't care about emotion that much. Females easily express or write negative things towards a person they did not know before, just like me to you." (A1)

"Intensifiers are used to explain more feelings or wishes. It's used to explain emotion and emphasize it." (A4)

In these females' responses, the use of basic and taboo intensifiers can show emotion especially anger or other negative feelings. However, a male participant, B1, believed that the use of intensifiers had no correlation with emotion. Using some expressions of intensifiers did not always present the real emotion. On the other hand, another male participant said the opposite way

"I used intensifiers to give explanation about my feeling. It was just something about my emotion." (B3)

In more details, the emotional intensifiers were divided into two conditions, either love or hatred feelings. In female cases, they argued that intensifiers could express hatred feelings best.

"Me and other females wrote many intensifiers to show emotion, especially in D-E topic. In topic D$E$, we might swear a lot and intensify a lot as it was the story about love or hate." (A3)

"'fucking jerk ass' here I wrote because I hated her so bad. I didn't know what else to say since she was the worst." (A2)

"Women did that everytime we see someone who we hate. I wrote 'so fucking selfish', it was seriously not about weird bad words / say sex related or so but it is just it is." (A3)
Males, however, mostly believed that intensifiers were the best expression in portraying loved feelings or admiration as in these revealed interview responses:

"Fucking was the strongest word I think. Ya, I wrote 'fucking cool' because i like him best and $i$ thought that it was about the most emotional intensifier." (B1)

"so fucking legend' was the best expression to fit what I wanted to say." (B3)

"I wrote 'damn cool' because I was really amazed yet it's not that best so I used only a single taboo." (B3)

"You know that it was me when I admired someone really bad, I used this expression 'so fucking cool." (B4)

Aside from telling love, hatred, or anger into the sentences, the intensifiers could also possibly portray sadness as found in the following sentence:

"I wrote 'totally sad' in this sentence because I felt sad in everything. Ya, that's what I felt so I said it." (A4)

\section{Societal Pressure}

The following reason motivating the use of intensifiers was related with societal pressure. This aspect was inferred from interview as in these quotations:

"I think males use taboo intensifier because it's a common thing in friendship." (B2)

From this talk, it could be inferred that society judged male friendship as the relation without strict communication rules like females. There was another societal pressure directed to males as can be inferred from this participant answer:

"I think males used simple intensifier because we were bad in giving expression." (B4)

This response is associated with the beliefs from society that males were worse at expressing something compared to females. Moreover, a similar point of view also stated by another male participant:

"In my opinion, me and other male participants used less various intensifiers because it's common culture among us." (B5)

He believed that males used less various intensifiers since it was a culture in society. This culture force from society possibly could indirectly dictate males or females to behave especially in language.

\section{Other reasons}

Additionally, several reasons here were also not acknowledged by previous scholars. Firstly, it was found in female case such as in this interview answer: 
"In telling intensifiers, I think, me and other females were easy to get attached. Also, maybe it was because I felt that I was breathing the same air as you, even though it's only from writing. That's why I was trying to bring so much caring with the flowing topic. In all these human adjectives, we intensified a lot because it was about mankind that we had to write carefully and in friendly ways." (A1)

From her opinion, it could be inferred that intensifiers could be a sign of caring or being friendly with the readers or hearers. Another reason was about the tendency of females in having more things to say or being verbose. It was proven as the presented data below:

'I used 'so much fucking fun' because I wanted to say that I did have so much more than the actual fun." (A1)

"I wrote 'so fucking mess up' since Ineeded more to say." (A2)

"This sentence explained Billie Eilish. 'very talented' means that she was one step further than everyone else. I used 'very' because I wanted to say more than basic." (A3)

"I used different choices of intensifiers because I wanted to be different from others and I always want to make it more (A5)

There was also a connection between the use of intensifiers and comparison structure. One of female participant said this thing:

'A word 'very' in very happy' means that it 's not that flat happy. I used very because I didn't want to use a word 'happiest." (A4)

Last, the reason found among females was as in this interview response:

"Ya, this one was about my feeling. I wrote kinda private' because the way of this method was like a diary of me to you. I used non formal writing and also applied many intensifiers." (A3)

From her opinion, it could be justified that she used many intensifiers because she just felt like she wrote in her diary.

In male side, only one other reason was found which could not be categorized into the previous five aspects. Here is the evidence from one of male participant's answer:

"Oh, I used intensifiers to explain situation. The word 'so' in this sentence, 'I forgot to pray and that was so bad', was meant to tell bad situation. "(B2)

By his statement, it could be inferred that intensifier was only used to give explanation about situation at the moment.

\section{CONCLUSION}

The use of intensifiers is always prevalent among teenagers. It is associated with the rich expressions and exaggerations produced by them. Therefore, they rely heavily on the use of intensifiers. In fact, the use of their intensifiers is different to some extents due to the gender role. This study found that the first significant difference was the total amount of intensifiers. In this study, females used intensifiers more frequently than males. The percentages of their use of intensifiers were higher than those of males in each topic. The next difference was about the modified adjective types. Females tended to intensify human related adjectives while males tend to intensify value adjectives. Intensifier so was found to be the most popular intensifiers among them. In human propensity adjectives, the most used intensifier among females was so while among males was so fucking. In value adjectives, fucking was the most popular intensifier among females while so was used in highest frequency among males.

The other differences found were about the intensifiers degree, positive-negative evaluation, and also emotional value. In the case of intensifiers degree, females were proven to use maximizer amplifier more frequently than males who preferred to use boosters. In addition, there were some expressions which were classified as double degree intensifiers. In male cases, maximizers plus boosters appeared once and boosters plus maximizers degree occurred quite frequently. In female cases, the only existed double degree intensifier was boosters plus maximizers. Secondly, in the case of positive-negative evaluation, females were recognized to express negative judgement more often than males. They applied negative intensifiers mostly to intensify the effect of human behaviour adjectives. In male cases, the higher percentage evaluation was devoted into positive judgement. In other words, males were found to use intensifiers to create positive sentence. Thirdly, in the case of emotional value, both males and females were revealed to have quite similar percentage. A thing that distinguished them was the choice in uttering emotion. Males preferred to use double intensifiers such as so or really which were followed by expletives fucking or damn to single intensifier while females preferred to choose single intensifiers such as totally or extremely to double intensifiers.

The next differences were about the word choices and the application of double and taboo intensifiers. Females used more various choices of intensifiers compared to males such as extremely, super, totally, hella, etc. Males were proven to use so as the most used intensifiers and the modification such as so fucking and so damn as the second and third most used intensifiers. 
In attitutes towards the application of double intensifiers, males employed this feature more $(70 \%)$ than females. In this case, double intensifiers were familiar among males. However, in another issue, the uses of taboo intensifiers were popular not only among males but also females. The expletives which were mostly found among males and also females were fucking and damn. Also, another new kind of expletive, hella, was discovered among females.

All of these differences were determined by several motives sourced from their perception of gender roles. The first motive was power. This study showed a different result as what have been observed by Lakoff (1975) who said that female would always be related with intensifiers in showing their power in interaction. Male participants in this study were the ones who used intensifiers to reveal their power in leading the talk and controlling over someone's behavior since they wanted to be heard. The second motive was politeness. All females in this study did not care about politeness norms. This result was actually in the opposite of what had been observed by Huddleston and Pullum (2002) whom say that females had to adjust the society's expectation to communicate politely. In this study, female participants could say taboo intensifiers whenever they wanted to say as forms of their expressions. The third motive was about expressions. All intensifiers dealt with intentions such as expressions of exaggeration, admiration, complaint, shock, and distastefulness. The fourth motive was emotion. This study also found that there were some objects of emotion which triggered the use of intensifiers such as emotion in love, hatred, and also sadness. All males and females were found to express these emotions interchangeably. The last motive was societal pressure. In this case, only males who were found to reveal their intensifiers with the intention of society force. The existence of societal pressures was reflected in the limited variety of intensifiers, for example, the uses of intensifiers very, really, so, were dominantly used among males and variations like extremely, perfectly, totally were not commonly found among them. The participants believed that society expected male to be less expressive than female, thus, restricting their choices of intensifiers. In addition, the common use of taboo intensifiers in males' friendship, and the judgement of bad expressions towards males were also the other societal pressures directed to males.

Along with all these motives, there were some other reasons which have not been revealed by the scholars. This study found that the motives in using intensifiers were also related with some justifications. A feeling of being in the same place and talking directly with the readers, a belief that intensifiers were a friendly sign, a sense of wanting to be different, an idea of verbose, an alternative way instead of using structure of degree and comparison, and a similar mood such as writing in diary were the other reasons discovered from the female participants. In male side, another motive found was a need to give explanation about the exact situation at the moment.

From the elaboration above, it can be concluded that the use of intensifiers is prevalent among teenagers which is revealed by the high amount of intensifiers written by all participants. Male and female teens wrote intensifiers in different ways and also purposes. Their dissimilarities on the use of intensifiers were revealed through different perception of gender roles among them. In short, males and females had their own insight beyond intensifiers they used which instigated the dissimilarities in writing especially about their choice of intensifiers and the intentions.

\section{REFERENCES}

Amir, Z., Abidin, H., Darus, S., \& Ismail, K. (2012). Gender differences in the language use of malaysian teen bloggers. GEMA Online: Journal of Language Studies, 12(1), 105-124.

Andersen, G. \& Hasund, I. K. (2002) Trends in teenage talk: Corpus compilation, analysis and findings. Amsterdam: John Benjamins Publishing Company.

Barnfield, K. \& Buchstaller, I. (2010). Intensifiers on Tyneside: Longitudinal developments and new trends. English World-Wide: A Journal of Varieties of English, 31(3), 252-287. doi: 10.1075/ eww.31.3.02bar.

Boncea, I.J. (2013). Hedging patterns used as mitigation and politeness strategies. Annals of the University of Craiova. Series: Philology-English, 14(2), 7-23.

Brown, P., \& Levinson, S. (1987). Politeness: Some universals in language usage. Cambridge: Cambridge University Press.

Bulgin, J., Elford, N., Harding, L., Henley, B., \& Power, S. (2008). So very really variable: Social patterning of intensifier use by Newfoundlanders online. Linguistica Atlantica. 29, 101-115.

Corey, O.J. (2014). Gender differences in intensifying modifiers: So, very, really, and pretty. Retrieved from https://www.semanticscholar.org/paper/ Gender-Differences-in-Intensifying-Modifiers\%3A-So-\%2C-Corey/69d81bfa5ed32452084a 49190b08a5efc7d1f2c8.

Dixon, R. M. W. (1977). Where have all the adjectives gone? Studies in Language 1, 19-80.

Eckert, P., \& Sally, M. G. (2003). Language and Gender. New York: Cambridge University Press. 
Greenbaum, S. (1974). Some verb-intensifier collocations in American and British English. American Speech, 49 (1/2), 79-89.

Holmes, J. (1992). An introduction to sociolinguistics. London and New York: Routledge

Huddleston, R. \& Pullum, G.K. (2002). The cambridge grammar of the English language. Cambridge: Cambridge University Press.

Karlsson, S. (2007). Gender-related differences in language use. Ph.D Thesis. Lulea University. Sweden.

Lakoff, R. T. (1975). Language and woman's place. New York: Harper \& Row.

Macaulay, R. (2006). Pure grammaticalization: The development of a teenage intensifier. Language Variation and Change, 18(3), 267-283. doi:10. 1017/S0954394506060133.

Mills, J., Bonner, A., \& Francis, K. (2006). The development of constructivist grounded theory. International Journal of Qualitative Methods, 5(1), 25-35. doi: 10.1177/160940690600500103.

Moore, R. (2012). On swearwords and slang. American Speech, 87(2), 170-189. doi: 10.1215/0003 1283-1668199.

Murphy, B. (2010) Corpus and sociolinguistics: Investigating age and gender in female talk. Amsterdam and Philadelphia: John Benjamins Publishing Company.

Núñez-Pertejo, P. \& Palacios-Martínez, I. (2018). Intensifiers in MLE: New trends and development. Nordic Journal of English Studies. 17(2), 116155.

O'Barr, W. M. (1982). Linguistic evidence: Language, power, and strategy in the courtroom. New York: Academic Press.

Palacios-Martínez, I. (2011). The language of british teenagers: A preliminary study of its main grammatical features. Atlantis: Journal of the Spanish Association of Anglo-American Studies, 33(1), 105-126.

Pérez-Paredes, P., \& Díez-Bedmar, M. B. (2012). The use of intensifying adverbs in learner writing.
In Y. Tono, Y. Kawaguchi, \& M. Minegishi (Eds.), Developmental and crosslinguistic perspectives in learner corpus research (pp. 105124). Amsterdam: John Benjamins Publishing Company.

Peters, H. (1994). Degree adverbs in early modern English. In D. Kastovsky (Ed.), Studies in Early Modern English, (pp. 269-288). Berlin: Mouton de Gruyter.

Quirk, R., et al (1985) A Comprehensive grammar of the English language. New York: Longman.

Saarenpää, T. (2016). A comparative corpus study on intensifiers in Canadian English and New Zealand English. MA Thesis. Finland: University of Tampere.

Sardabi, N. \& Afghari, A. (2015). Gender differences in the use of intensifiers. Journal of Applied Linguistics and Language Research, 2(7), 203213.

Sari, C. M. I. (2015). An analysis of apology as a politeness strategy expressed by the characters in the film "Princess Diaries 2": A socio pragmatic approach. Humaniora Scientia, 2(1), 1-12.

Schwizer, N. (2014). Intensifiers: An actively changing feature in present-day english: The degree words damn, bloody, fucking, very, really and so. A corpus-based apparent-time study (BNC). Seminar Paper: Changes in Present-Day English (Autumn Term 2013). Zürich.

Tagliamonte, S. A. (2008). So different and pretty cool! Recycling intensifiers in Toronto, Canada. English Language and Linguistics, 12(2), 361394. doi: 10.1017/S1360674308002669

Wardhaugh, R. (2006). An Introduction to Sociolinguistics. Malden, Mass., USA: Blackwell

Weatherall, A. (2002). Gender, Language and Discourse. London: Routledge.

Weatherall, A. (2016). Language and Gender. In N.A. Naples, et al. (Eds) The Wiley Blackwell Encyclopedia of Gender and Sexuality Studies (pp. 15). Chicester: John Wiley and Sons. Doi: 10. 1002/9781118663219.wbegss145. 